\title{
19
}

\section{BMP Economics and Sizing}

\author{
Ben Urbonas, Christopher C. Olson, Ken MacKenzie and James C.Y \\ Guo
}

Stormwater quality management is a mandated practice in the United States by the Clean Water Act of 1972 and the interpretation of this law by the U.S. Environmental Protection Agency (USEPA) through its Municipal Separate Stormwater Sewer System (MS4) permit program. This MS4 program is driving the use of best management practices (BMPs) for the management of stormwater runoff, including a subset of these called low impact development (LID practices). In attempting to comply, various states and local governments (jointly referred as communities) instituted programs requiring a range of stormwater treatment and disposal facilities, namely BMPs, including the use of LID installations. Often, these requirements were imposed without considering the long term effectiveness and economics of the decision. The latter is crucial for communities to know since by law they are required to ensure that the BMPs they approve for installation will continue to function as designed in perpetuity, or until replaced by new facilities.

Few analytical tools exist to help communities assess which BMPs are most effective under their site conditions and what will be the long term budgetary implication of these selections. For example, the USEPA's SUSTAIN model (Shoemaker, et.al., 2009) incorporates sophisticated algorithms for evaluating BMP effectiveness, but its default cost functions are limited only to construction costs and its use requires a relatively high level of technical expertise. The Water Environment Research Foundation's Performance and Whole Life Costs of BMPs and SUDS spreadsheet tools (Lampe et al., 2005) can be used to estimate the whole life costs of a single BMP at a time; however, they lack BMP effectiveness algorithms. Neither of these explicitly account for the inflation of maintenance, operation and administrative costs.

Urbonas, B., C.C. Olson, K. MacKenzie and J. Guo. 2013. "BMP Economics and Sizing." Journal of Water Management Modeling R246-19. doi: 10.14796/JWMM.R246-19.

(C) CHI 2013 www.chijournal.org ISSN: 2292-6062 (Formerly in Pragmatic Modeling of Urban Water Systems. ISBN: 978-0-9808853-8-5) 
Recognizing these shortcomings, the Urban Drainage and Flood Control District (UDFCD) in Denver, Colorado and the Urban Watersheds Research Institute, Inc. partnered in funding Colorado State University to develop the BMP Rational Estimation of Approximate Likely Costs of Stormwater Treatment (BMP-REALCOST) model (UDFCD, 2010). The model is available from UDFCD at http://udfcd.org/downloads/software/BMP-REALCOST v1.0.zip, along with its user manual, as a free download. The model is Excel based, is relatively open source, and is easy to use. It permits the user to assess and adjust, as needed, various program parameters. The economic analysis accounts for inflation and variations of construction and maintenance costs by location using the Engineering News-Record construction cost index (ENR $\mathrm{CCI}$ ). This chapter analyzes $10 \mathrm{BMP} / \mathrm{LID}$ types when applied to a $1 \mathrm{mi}^{2}$ urban watershed in Denver, Colorado to illustrate how BMP-REALCOST can be used by communities to compare BMPs and LID practices when determining what they will accept or approve.

\subsection{Application of BMP-REALCOST Model}

\subsubsection{Land Uses within the Example Watershed}

The BMP-REALCOST model was used to test a series of BMP applications. Each scenario examined a single BMP type applied uniformly within the $1 \mathrm{mi}^{2}$ watershed. The results can be used by planners, decision makers and regulators to inform their choices of BMP types, specifically in terms of effectiveness in controlling stormwater runoff, long term maintenance and rehabilitation costs, and administrative costs. The example watershed contained a mix of commercial, multi-family residential, and two different densities of single family residential land uses; see Table 19.1 for a summary of the land uses along with their assigned effective imperviousness. This table also lists the per acre cost of land for each of the land uses in the example.

Table 19.1 Land use distributions, effective imperviousness and land costs.

\begin{tabular}{llccc}
\hline \multicolumn{1}{c}{ Catchment ID } & \multicolumn{1}{c}{ Land Use } & $\begin{array}{c}\text { Area } \\
(\mathrm{ac})\end{array}$ & $\begin{array}{c}\text { \% Effective } \\
\text { Impervious }\end{array}$ & $\begin{array}{c}\text { Land Cost } \\
\$ / \mathrm{ac}\end{array}$ \\
\hline Cross Roads & Commercial & 50 & $95 \%$ & $\$ 200000$ \\
Shop \& Go & Commercial & 15 & $95 \%$ & $\$ 200000$ \\
Apartments & Residential - Apartments & 100 & $80 \%$ & $\$ 200000$ \\
Residential 1 & Residential 3 $000 \mathrm{ft}^{2}$ homes & 225 & $51 \%$ & $\$ 130000$ \\
Residential 2 & Residential 2 $000 \mathrm{ft}^{2}$ homes & 250 & $39 \%$ & $\$ 130000$ \\
\hline
\end{tabular}




\subsubsection{Economic Considerations and Modeling Parameters}

Since BMPs are intended to perform in perpetuity, they will need to be maintained and rehabilitated as necessary. To make cost comparisons, a long economic life, say $50 \mathrm{y}$, is appropriate and is representative of many public works projects. Therefore, to facilitate direct comparison of the BMP scenarios, all costs over a 50 y lifecycle were reduced by the model to a net present cost (NPC) after accounting for inflation and discounted interest rate. An inflation rate of $4.6 \%$ was used, which is the average of published rates over the last $50 \mathrm{y}$ in the United States. The interest rate for invested municipal funds was assumed to be $5.0 \%$; a rate that is little higher than the inflation rate and one that appears reasonable when looking at the municipal bond rates over the last $20 \mathrm{y}$ to $30 \mathrm{y}$ (although returns in 2011 are much lower). A 2009 ENR CCI index of 6570 was applied to adjust the costs for the Denver region. All default construction and maintenance cost parameters in BMP-REALCOST were input using the 2009 national ENR CCI of 8 141, but some default costs were overwritten (a capability allowed by the model) by the authors to reflect differences in capital and maintenance costs between BMPs that require underdrains and those that do not. Administrative costs, namely the cost of complying with for the MS4 permit were assumed to be $12 \%$ of the annual maintenance costs plus the cost of regular inspections.

The construction costs for each BMP were developed for UDFCD (Muller Engineering, 2009). These costs were increased by $40 \%$ to account for contingencies, cost of planning, engineering, inspection, and discharge permit oversight during construction, none of which were part of Muller's estimate.

\subsubsection{Hydrologic Conditions Used for Sizing of BMPs}

In developing this example, BMPs were sized using protocols recommended for the Denver region. These included the complete capture and treatment of the 80th percentile runoff event for storage BMPs and the processing of storms up to the 2 y design storm for conveyance BMPs (UDFCD, 2004). Mean annual precipitation is $15.8 \mathrm{in}$. (401 mm), the $2 \mathrm{y} 1 \mathrm{~h}$ depth is $0.95 \mathrm{in}$. (24 mm) and the mean storm depth is 0.43 in. (11 mm) (Driscoll et. al., 1989).

\subsubsection{BMPs Modeled}

Table 19.2 lists the numbers of each BMP, by type, used in this example $1 \mathrm{mi}^{2}$ watershed. It is believed that the densities for onsite (i.e. lot based) control BMPs that were used in this example were somewhat low. Also listed are the 
years between rehabilitations, or periods needed to rebuild or completely recondition each facility, along with the percentages of the original capital cost used as the cost of rehabilitation for each BMP.

Table 19.2 Number of BMPs modeled per square mile and rehabilitation assumptions.

\begin{tabular}{llccc}
\hline \multicolumn{1}{c}{ BMP Type } & $\begin{array}{c}\text { No of } \\
\text { BMPs }\end{array}$ & $\begin{array}{c}\text { Years Rehab } \\
\text { Cycle }\end{array}$ & $\begin{array}{c}\text { Rehab } \\
\text { Cost of } \\
\text { Capital }\end{array}$ \\
\hline EDB & Extended detention basin (dry) & 27 & 35 & 50 \\
RP & Retention ponds (wet) & 18 & 35 & 80 \\
SFB-u & Sand filter basin w/underdrain & 27 & 25 & 75 \\
SFB-i & Sand filter basin w/infiltration & 27 & 25 & 80 \\
RG-u & Rain garden w/underdrain & 543 & 15 & 30 \\
RG-i & Rain garden w/infiltration & 543 & 15 & 30 \\
PICP-u & Porous interlocking concrete paver w/underdrain & 131 & 25 & 80 \\
PICP-i & Porous interlocking concrete paver w/infiltration & 131 & 25 & 80 \\
HS & Hydrodynamic device & 355 & 25 & 100 \\
II & Inlet insert & 709 & 2 & 100 \\
\hline
\end{tabular}

In total ten BMP types were analysed, with some only differing by whether the captured runoff is infiltrated or discharged to the surface via underdrains. Infiltration is not available in all cases for reasons such as geology, groundwater levels, geotechnical limitations near structures, potential for flooded basements or polluted groundwater plumes.

\subsection{Results for Example Watershed}

\subsubsection{Reductions in Runoff Volumes and Pollutant Loads}

Based on BMP-REALCOST results, the relative effectiveness of the BMPs in reducing annual surface runoff volumes and total suspended solids (TSS) loads are compared in Figure 19.1. All of these estimates are based on the data and reports obtained from the International BMP Database: www.bmpdatabase.org. Four levels of performance emerge:

1. BMPs with water quality capture volume (WQCV) that infiltrate the runoff into the ground, namely, SFB-i (90\%\%), RG-i (86\%) and PICP-i (85\%) appear to have the best performance in runoff volume (shown in parentheses) and pollutant load reductions;

2. BMPs with WQCV that filter the runoff, namely, SFB-u (36\%), RG-u (51\%) and PICP-u (35\%) with underdrains have the 
second best performance in runoff volume (shown in parentheses) and pollutant load reductions;

3. BMPs with WQCV that release the captured runoff over an extended period of time, namely, EDB (27\%) and RP (6\%), and have the third best performance in reducing runoff volumes (shown in parentheses) and pollutant loads; and

4. The flow-through BMPs without a WQCV, namely II and HS, provide zero reductions in runoff volumes and have the lowest levels of pollutant load reductions.

\% Reduction in Runoff Volumes

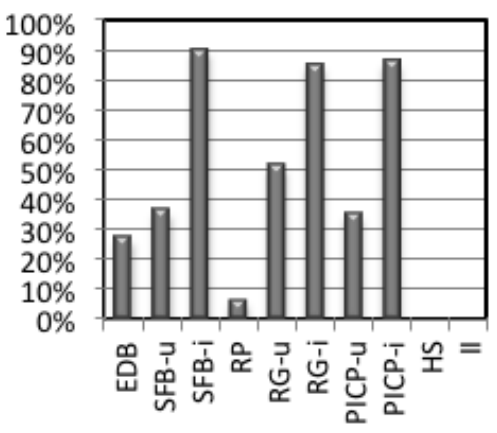

BMP TYPE
\% TSS Load Removed

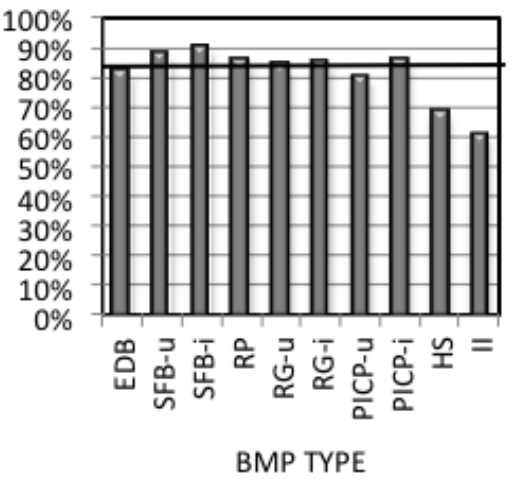

Figure 19.1 Annual runoff volume (left) and TSS load (right) reductions.

All the estimates in runoff volume and pollutant load reductions are based on the data reported by the USEPA's Nationwide Urban Runoff Program (USEPA, 1983), subsequent data collected by a number of local governments for USEPA during MS4 permit applications, and the runoff volume and effluent event mean concentrations (EMCs) reported by the International BMP Database (Wright Water Engineers and Geosyntec, www.bmpdatabase.org). These data were supplemented by data and experience gathered in the Denver region by the UDFCD. The pollutant removal percentages in shown in Figure 19.1 were calculated by the model using mean influent and effluent concentrations reported in above-mentioned references.

\subsubsection{Effects of Inflation on Net Present Costs}

Often BMP selection is done on the basis of the initial costs of planning, design, construction and engineering. However, as noted above, communities also need to look at the long term costs over the entire economic life of the 
BMP. Over the full life cycle of a BMP installation, inflation plays a major role in defining the net present costs (NPCs) of each installation to the community and its resources. Figure 19.2 illustrates one of the figures produced by BMP-REALCOST and shows the effects of the 50 y average $4.6 \%$ inflation rate on maintenance and administrative costs on rain gardens (RGs) spread uniformly across the $1 \mathrm{mi}^{2}$ urban watershed. As can be seen, the maintenance and administrative costs over 50 y are significant, totalling over $\$ 15 \mathrm{M}$ in today's dollars, which far exceeds the initial cost of the rain garden installations.

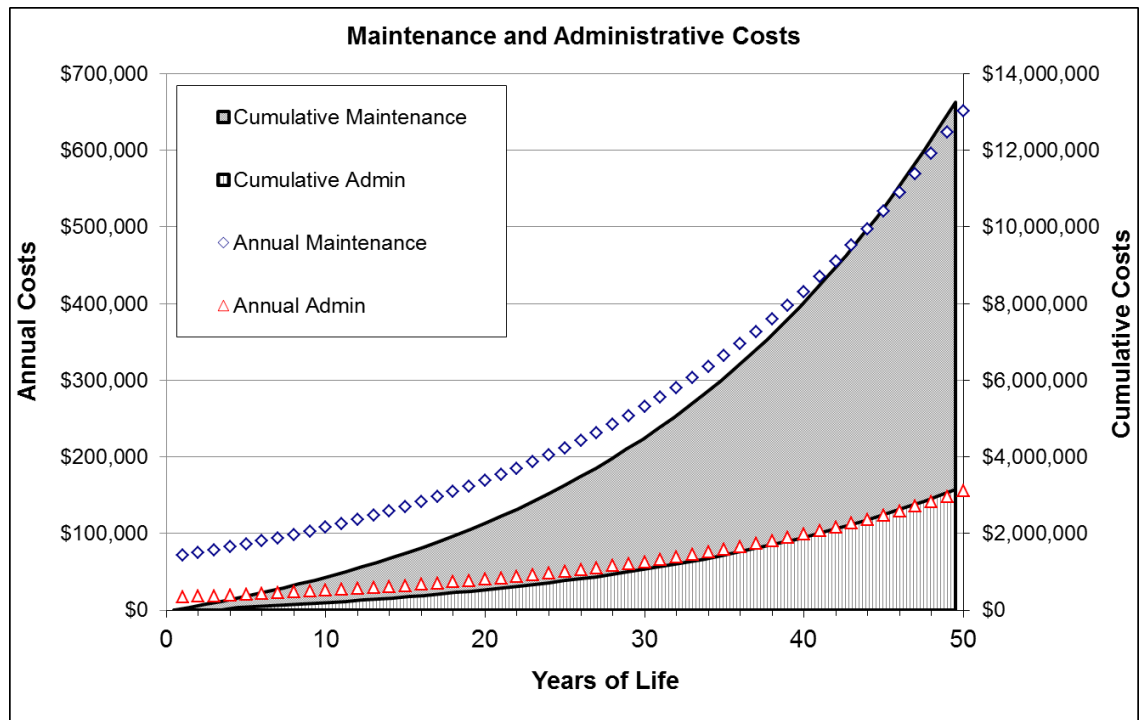

Figure 19.2 Effects of inflation on maintenance and administrative costs for a system of RGs over $1 \mathrm{mi}^{2}$ urban area in Denver, Colorado.

\subsubsection{Total Net Present Costs of BMP Types}

The NPC of a BMP system over its economic life includes all of the costs discussed earlier, namely planning, design, construction, construction observations, review processes, maintenance, rehabilitation, and administration of the program. The costs that are incurred and adjusted for inflation over time are then converted to the NPC by applying the discount rate (interest rate for municipal investments), which in this case was estimated at $5 \%$, as presented previously. Figure 19.3 shows a comparison for the BMPs in this example and provides the decision makers with cost information that can help to decide which BMPs will serve their community most economically. However, cost is 
only one factor, one that has to be balanced against the effectiveness of each BMP in removing pollutants and controlling surface runoff described earlier and illustrated in Figure 19.1 above.

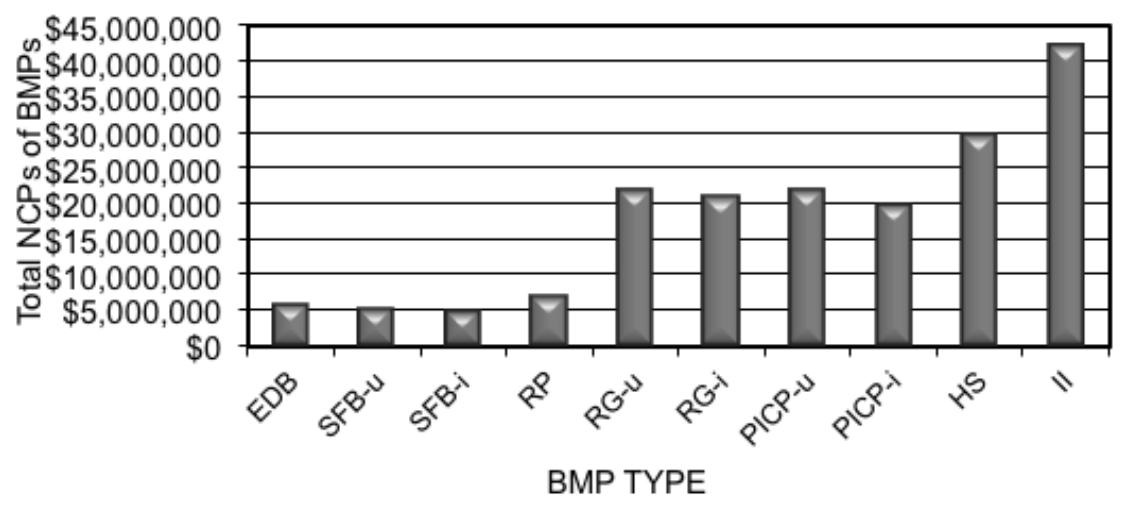

Figure 19.3 Net present cost of BMP systems for $1 \mathrm{mi}^{2}$ urban area, 50 y economic life (PICP costs account for conventional pavement offset-see section 19.2.5).

\subsubsection{Cost Effects of BMP Density}

Examining Figure 19.3 and comparing BMP types to their densities in the watershed reported in Table 19.2, we see that there is a direct relationship between BMP density within a watershed and the systemwide NPCs. Namely, greater densities of BMPs result in higher systemwide NPCs. This is because construction, land and maintenance costs are not directly proportional to BMP size (i.e. economies of scale) and there are fixed costs for each facility regardless of size. BMPs with the lowest NPCs fall into a category of community based, or regionalized, BMPs and include extended detention basins (EDB), retention ponds (RP) and sand filter basins (SFB). The BMP with the highest NPCs, which we termed as lot based, included the PICP discussed earlier and hydrodynamic separators (HS), inlet inserts (II), and rain gardens (RGs).

\subsubsection{Case of Porous Interlocking Concrete Pavers vs Conventional Pavement}

When considering porous interlocking concrete pavers (PICPs), it is important to account for the fact that PICPs replace the need for conventional pavement. Therefore, there is a cost offset unique to PICP applications that must be accounted for in NPC comparisons. Without the cost offset, PICP had the 
highest apparent net present costs (NPC) of all BMPs modeled. This can be seen in Figure 19.4, which compares NPC unit costs with and without the cost offset. The cost offset is calculated as the NPC of equivalent areas of non-permeable pavements. Such adjustments can result in 50\% to $100 \%$ reductions in the NPC of PICPs. It is also important to note that this offset is conservative, as it does not account for costs associated with the larger drainage systems which may be needed when PICPs are not used.
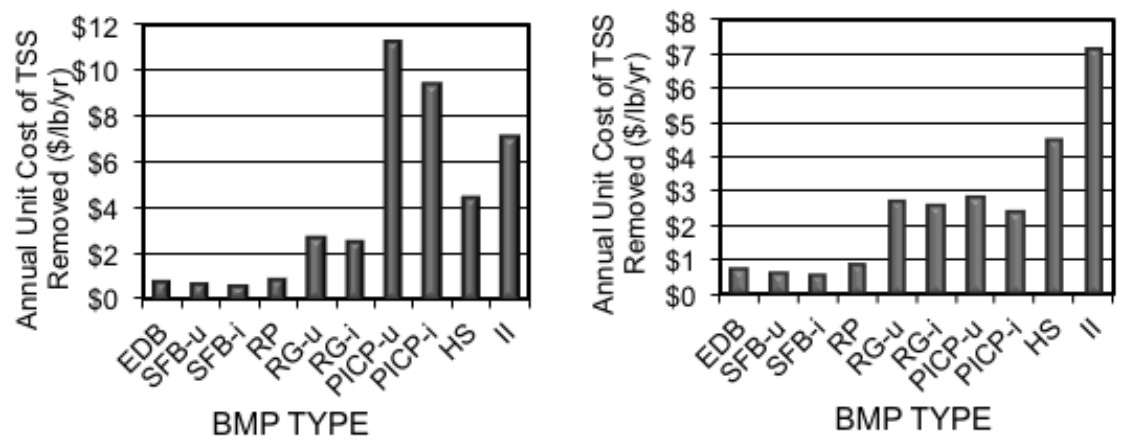

Figure 19.4 Annual unit NPC of $1 \mathrm{lb}$ TSS removed by PICP BMP from $1 \mathrm{mi}^{2}$ urban area before (left) and after (right) adjusting for the cost of convectional pavement.

\subsection{Sizing of the Water Quality Capture Volume}

Given the potential cost implications of BMPs, there is a clear need to find the optimal water quality capture volume (WQCV) for each type of BMP. If undersized, the receiving waters will not see the mitigations benefits to protect their aquatic life and geomorphology. If oversized, valuable land and fiscal resources will be wasted. Continuous simulation is typically the most reliable way to size a WQCV basin: using long term rainfall data to generate runoff and then routing it through the BMP's WQCV basin (see Figure xx5). The size of the basin is, in part, a function of its drain time (i.e. the time it takes to dewater a brim full WQCV basin). This defines the average discharge flow rate through the basin's outlet, underdrain, or through infiltration into the ground.

\subsubsection{Point of Diminishing Returns}

The idea of quantifying the point of diminishing returns for BMP sizing was suggested by Urbonas, Guo and Tucker in 1990 (Urbonas et.al., 1990). This concept was further developed and tested by Guo and Urbonas using continuous rainfall data at a variety of locations in the United States (Guo and 
Urbonas, 2002). Since then UWRI, UDFCD and the University of Colorado, Denver developed a water quality capture optimization statistical model (WQCOSM) to allow for easy and efficient analysis of the rainfall-runoff volume process using National Climatic Data Center (NCDC) data. WQ-COSM is available at http://www.urbanwatersheds.org/software/software.html.

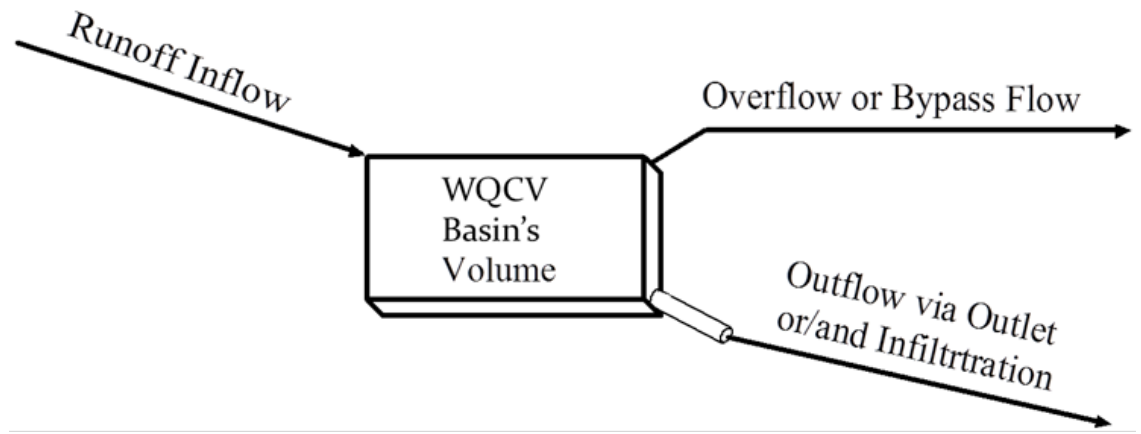

Figure 19.5 Schematic of the routing process through a WQCV basin.

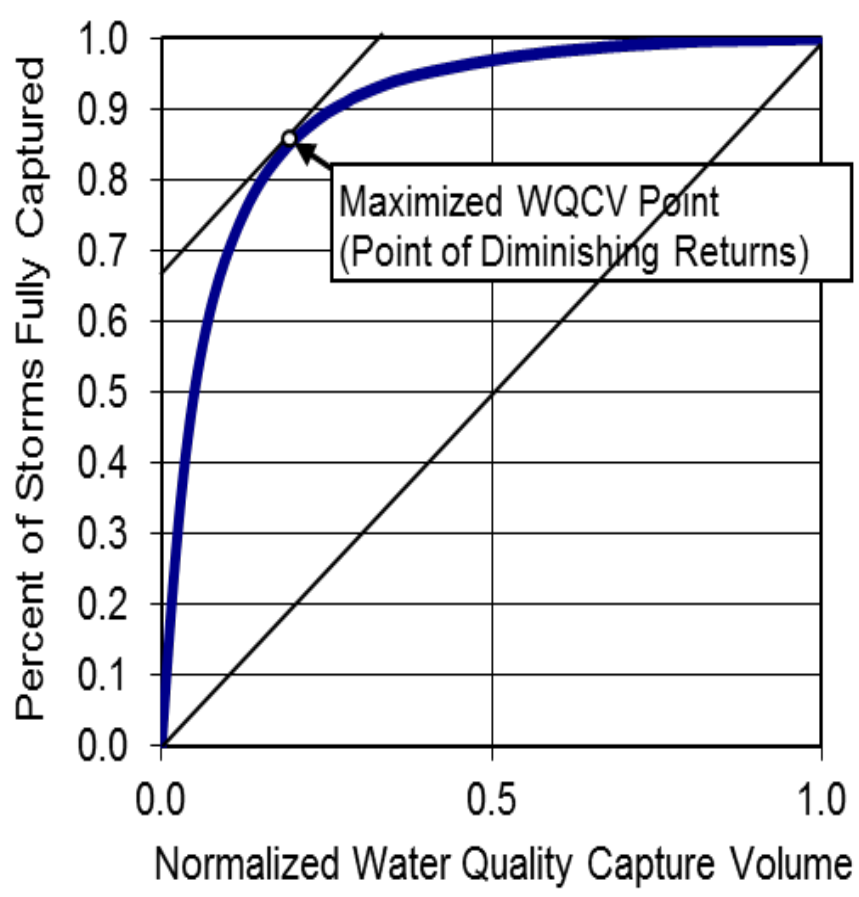

Figure 19.6 Point of diminishing returns (Urbonas et.al., 1990). 
WQ-COSM generates an array of WQCVs up to a size that captures $100 \%$ of all runoff volumes and runoff events. It also identifies the point of diminishing returns (i.e. optimized WQCV) in terms of the total volume captured and the number of storms captured. Up to that point, incremental increases in WQCV basin size result in corresponding favorable returns in terms of incremental increases in the volumes of runoff and the number of storms captured. Beyond that point, incremental increases in WQCV result in rapidly diminishing returns in the capture volumes and captured storms. Figure 19.6 above illustrates this phenomenon, which was found to occur at all the locations throughout the United States examined by the authors.

To find this point of diminishing returns, all incremental WQCV basin sizes are normalized by the WQCV that fully captures all of the runoff volumes or storm events. Since a few very large events can skew the results, the software allows the user to mitigate this by defining the largest WQCV value to be used (i.e. exclude the largest events), say greater than the 99.5th percentile WQCV.

\subsubsection{Modeling Surface Runoff}

WQ-COSM provides three options for estimating surface runoff volumes, namely rational, integrated Horton's and Green-Ampt methods. The latter two use algorithms similar to those used in USEPA's SWMM. NCDC continuous $15 \mathrm{~min}$ and $60 \mathrm{~min}$ precipitation data is read and checked for errors by the program. The user may exclude specific seasons, such as snow months, and very small storms from analysis. Rainfall and runoff volume statistics and, if desired, information about each storm are provided as output.

\subsubsection{Counting Total Runoff and Number of Events Captured}

If the cumulative runoff volume being stored within the WQCV vessel during any storm event does not exceed the basin's capacity, the runoff volume for that event is considered to be entirely captured. If the runoff during a storm causes the basin's capacity to be exceeded, some of the runoff overflows or bypasses the basin. The incremental volume that overflows or bypasses is added to the cumulative total overflow volume. Two capture ratios are defined.

The runoff volume capture ratio is:

$$
R_{v}=1.0-\left(P_{t o} / P_{t r}\right)
$$

where:

$$
R_{v}=\text { runoff volume capture ratio, }
$$


$P_{t r}=$ cumulative runoff volume (in.), and

$P_{t o}=$ cumulative overflow or bypass volume of runoff (in.).

The runoff event capture ratio is:

$$
R_{n}=1.0-\left(N_{t o} / N_{S}\right)
$$

where:

$R_{n}=$ runoff event capture ratio,

$N_{t o}=$ total number of storm events where runoff exceeded the basin's capacity, and

$N_{s}=$ total number of storm runoff events.

This bifurcated definition permits the user to decide if the number of storms captured is more important to control than the total runoff volume over the period of simulation. Control of runoff volumes may not have a direct relationship to the receiving water response, as water quality impact is a function of multiple stressors. Further, if a few large events in the series are allowed to control the WQCV sizing, the result may be the targeting of events that produce unmanageable runoff volumes. Sizing for the capture of a specific percentage of runoff events may be more representative for mitigating water quality impacts and the effects of urbanization. This topic needs more serious field research, and should not be based on modeling and opinion only.

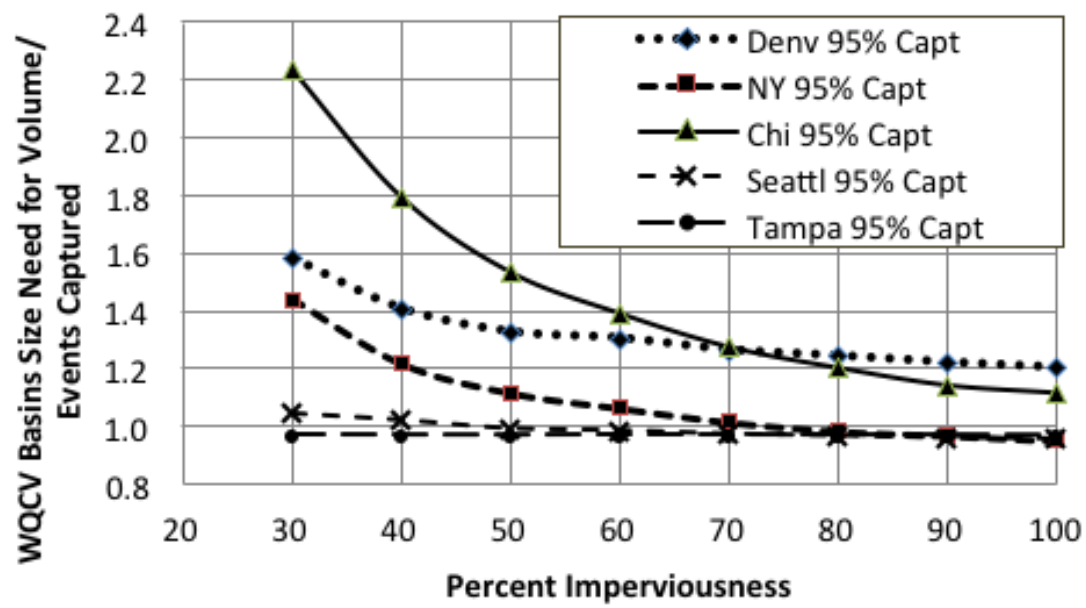

Figure 19.7 Ratios of 95\% (volumes)/(events captured) for WQCV basin sizing needs.

However, there can be a significant difference in both size and cost when the WQCV basin is sized to capture a defined percentage of volume instead of that same percentage of runoff events in total. Based on analysis 
using WQ-COSM, Figure 19.7 above shows a comparison for five cities in the United States; showing the ratio between the basin sizes of volume based versus event based captures at the $95 \%$ level. Depending on the location and the catchment's imperviousness, differences can range from zero to as much as $120 \%$ larger BMP basin size needed when the sizing is the result of volumebased WQVC calculations.

\subsubsection{Examples of Application of WQ-COSM}

WQ-COSM was used to assess the WQCV basin sizing needs at five cities in the United Sates, namely Chicago, Denver, New York, Seattle and Tampa. It is safe to conjecture that the receiving waters, and their needs for mitigation due to the effects of urbanization, vary greatly among of these locations. Thus a single capture-retention standard will fail to recognize the variety in their needs.

Also, as noted above, there is a good argument to screen out those capture volumes needed to fully capture large outlier (flood and drainage problem producing) storm events when sizing WQCV basins. Outlier events can skew the sizing upward and are not an appropriate target when the goal is to mitigate runoff effects on receiving waters. These extreme events have runoff impacts regardless of whether the catchment is urbanized or not. A reasonable suggestion for screening out these outliers is to limit the maximum WQCV size to capture $99.5 \%$ of volumes or events, and to screen out events larger than $99.5 \%$ from further analysis. WQ-COSM provides the users such an option and lets them to decide what this upper screening value is.

This approach was used for an example analysis of the five locations, after screening our WQCV basin sizing events exceeding a 99.5\% capture rate. After screening, the 95\% capture volume-based and event-based results were compared, as summarized in Figure 19.7 above.

Next, the question was asked: What is the additional sizing (and cost) penalty for capturing $95 \%$ of runoff volumes and events as opposed to capturing the volume at the point of diminishing returns? Table 19.3 lists the combined effect of sizing for the $95 \%$ values and for volume based instead of event based captures. As was expected there was much variability, ranging from as little as $40 \%$ penalty in Seattle to a $220 \%$ penalty in sizing in Denver. Clearly, much research is needed to answer What is the appropriate cost effective WQCV basin (i.e. for BMPs and LID) sizing protocol to effectively mitigate the most serious impacts of urbanization on receiving waters? Having a simple single, one-size-fits-all standard, or regulation, is likely to lead to unnecessary and excessive fiscal and land area expenditures and the waste of valuable resources. 
Table 19.3 Cumulative ratios of oversizing past the point of diminishing returns for volumes instead of events captured for a $60 \%$ impervious catchment.

\begin{tabular}{lcc}
\hline & City & Combined Ratio of WQCV Increase \\
\hline Chicago & 2.1 \\
Denver & 3.2 \\
New York & 1.5 \\
Seattle & 1.4 \\
Tampa & 1.75 \\
\hline
\end{tabular}

\subsection{Observations}

When selecting and sizing a stormwater quality control facility, one must balance the needed runoff capture volumes, effectiveness in protecting receiving waters, and life cycle facility costs. It is imperative that any economic analysis includes the costs of planning, engineering, construction and construction management, permitting, maintenance, eventual rehabilitation, and administration, all adjusted for the effects of inflation. Two easy-to-use, publicly available freeware models can help decision makers with this process: BMPREALCOST and WQ-COSM.

BMP-REALCOST is a relatively simple desktop model which provides estimates of the reductions in runoff volumes and in pollutant loads. It also estimates whole life cycle costs that consider the costs for planning, design, construction, maintenance, rehabilitation and administration. All costs can be adjusted for inflation and geographic locations in the United States using the ENR CCI.

When BMP-REALCOST was applied to an example case, a clear trend that emerged was that the net present cost of BMPs is a function of their density in the watershed; the higher the density, the higher the net present $\operatorname{cost} / \mathrm{mi}^{2}$. The lot based BMPs such as rain gardens, permeable interlocking concrete pavement, hydrodynamic separators and inlet inserts exhibited significantly higher NPCs than community based BMPs such as extended detention basins, sand filter basins and retention ponds.

As to water quality, some of the community based BMPs, such as sand filter basins, were as robust in reducing loads as rain gardens, while extended detention basins were almost as robust as permeable interlocking concrete pavements and sand filter basins with underdrains.

When communities consider which BMPs to use, it is important to consider not only initial capital costs, but also the long term maintenance and administrative costs. While parties involved in land development will naturally 
favor BMPs with the lowest initial costs, communities also need to look at the long term maintenance and rehabilitation commitments under their stormwater discharge permit requirements. Figure 19.2 above illustrates the effects of inflation on the escalation of maintenance costs.

A prescribed WQCV is an integral part of all BMPs that control runoff volume. The continuous simulation software WQ-COSM, developed jointly by the Urban Watersheds Research Institute, the Urban Drainage and Flood Control District and the University of Colorado, Denver provides easy-touse continuous simulation and calculation of water quality capture volumes for locations where NCDC continuous precipitation data are available. The simple maximization techniques developed by the authors, as illustrated in Figure 19.6 above, can help designers find the most cost effective WQCV for their community or specific client.

Finally, it is suggested that the most economical design is generally based on the percentage of events captured instead of the percentage of runoff volume captured over the period of analysis, and that the extremely large outlier storm events should be screened from the analysis as they will skew the WQCV basin size upward.

\section{References}

Driscoll, E.D., Palhegyi, G.E., Strecker, E.W. and Shelley, P.E. (1989). Analysis of Storm Events Characteristics for Selected Rainfall Gauges Throughout the United States. USEPA, Washington D.C.

Guo, James C.Y. and Urbonas, Ben. (2002). "Runoff Capture and Delivery Curves for Storm Water Quality Control Designs", ASCE J. of Water Resources Planning and Management, Vol 128, Vo. 3, May/June.

Lampe, L., Andrews, H.O., Hollon, M., Jefferies, C., Kellagher, R. and Matin, P. 2005. "Performance and Whole-Life Costs of Best Management Practices and Sustainable Urban Drainage Systems". Water Environment Research, Water Environment Research Foundation, Alexandria, VA.

Muller Engineering Company Inc. (2009). "Memorandum - Permanent BMP Construction Cost Estimates". Prepared for Urban Drainage and Flood Control District, Lakewood, CO.

Shoemaker, L., Riverson, J., Alvi, K., Zhen, J.X., Paul, S. and Rafi, T. (2009). SUSTAIN - A Framework for Placement of Best Management Practices in Urban Watersheds to Protect Water Quality. National Risk Management Research Laboratory, USEPA, Cincinnati, $\mathrm{OH}$.

Urban Drainage and Flood Control District (UDFCD). (2004). Urban Storm Drainage Criteria Manual, Volumes 1-3. Denver, CO. 
Urbonas, B.R., C.Y. Guo, and L.S. Tucker (1990). Optimization of stormwater quality capture volume. Urban Stormwater Quality Enhancement. American Society of Civil Engineers.

USEPA. (1983). Results of the Nationwide Urban Runoff Program, Final Report. U.S. Environmental Protection Agency. National Technical Information Service (NTIS) Access No.áPB84 18552. Washington, D.C.

Wright Water Engineers and Geosyntec. International BMP Database. www.bmpdatabase. org 
